\section{Embolism detected by transoesophageal echocardiography during hip arthroplasty}

Noëlle D. Lafont MD, Willy M. Kostucki MD,* Philippe H. Marchand MD, Michel N. Michaux MD, $\dagger$ Jean G. Boogaerts MD PhD
This case report demonstrates embolization of echogenic material detected by transoesophageal echocardiography during a cemented total hip arthroplasty in a 76-yr-old woman without patent foramen ovale. During the placement of the acetabular and femoral components, and during relocation of the hip joint, a "snow flurry" appearing in the right atrium was followed by several highly echogenic and mobile emboli of various sizes, some of them with a vermiform shape 1 to $5 \mathrm{~cm}$ long. At skin closure, echogenic material was seen in the right branch of the pulmonary artery adherent to the vascular wall of the bifurcation of the main pulmonary artery. No changes were observed in any haemodynamic variable monitored (heart rate, systemic and right atrial pressures). Also, no desaturation was detected by pulse oximetry and blood gases at the time of embolism and there was no decrease in $\mathrm{PETCO}_{2}$. This case report is in line with other studies which failed to show a haemodynamic impact of TEE detected emboli during THA.

Ce cas clinique démontre l'embolisation de matériel échogène détecté par échocardiographie transoesophagienne (ETO) à l'occasion de la mise en place d'une prothèse totale de hanche (PTH) cimentée chez une patiente de 76 ans sans foramen ovale perméable. Durant la mise en place des composants acétabu-

\section{Key words}

COMPLICATIONS: pulmonary embolism;

MONITORING: echocardiography, transoesophageal; SURGERY: orthopaedic.

From the Department of Anesthesiology and Intensive Care, Reine Fabiola 73 avenue de Centenaire, 6061 Montignies-surSambre, Belgium; and the *Department of Cardiology, André Vésale Hospital, 706 rue de Gozée, 6110 Montigny-le-Tilleul, Belgium; and the †Department of Orthopedy, Reine Fabiola Hospital, 73 avenue du Centenaire, 6061 Montignies-surSambre, Belgium.

Address correspondence to: Dr. N. Lafont, Department of Anesthesiology and Intensive Care, Reine Fabiola Hospital, 73 avenue du Centenaire, 6061 Montignies-sur-Sambre, Belgium.

Accepted for publication 11th May, 1994. laire et fémoral, ainsi qu'à la réduction de la hanche, est apparue une image de "tempête de neige "dans l'oreillette droite suivie d'emboles vermiformes de taille variable pouvant atteindre I à $5 \mathrm{~cm}$ de long. Durant la fermeture, du materiel embolique $a$ été mis en évidence au niveau de la bifurcation de l'artère pulmonaire, adhérant à la paroi vasculaire. Aucune répercussion hémodynamique (rythme cardiaque, pressions artérielle et veineuse centrale) a n'a été observée. De même, aucune désaturation détectée par oxymérie de pouls et gazométrie artérielle n'a été constatée. La PETCO $\mathrm{C}_{2}$ est restée stable. Ce cas clinique, en accord avec d'autres études, souligne que limpact hémodynamique des emboles détectés par ETO au cours de PTH cimentées est faible.

Bone cement implantation during total hip arthroplasty (THA) has been associated with venous embolism detected with transoesophageal echocardiography (TEE). ${ }^{1,2}$ Embolism of intramedullary debris is the most consistent factor, as shown in results of animal and human studies. $^{3-5}$ The consequences of right heart and pulmonary embolization of this material are not fully established. Ereth et al. have shown that the degree of embolization did not correlate with changes in haemodynamic variables nor did it result in persistent ventilation-perfusion mismatching. ' This case shows the absence of haemodynamic consequences of a large amount of echogenic material that was embolized into the right heart and partially entrapped in the pulmonary artery, illustrating the forgiving nature of the pulmonary bed.

\section{Case report}

A 76-yr-old, 77-kg, ASA II woman was scheduled for THA. In her past medical history she reported a cholecystectomy and an appendicectomy. She also suffered from systemic hypertension treated with beta-blocking agents.

Premedication with atropine sulphate $0.25 \mathrm{mg}$ im was administered one hour before surgery. Anaesthesia was induced with etomidate $20 \mathrm{mg}$ and fentanyl $100 \mu \mathrm{g} i$. Muscle relaxation was induced with pancuronium $6 \mathrm{mg}$ and anaesthesia was maintained with halothane in a mixture of $50 \% \mathrm{O}_{2}: 50 \% \mathrm{~N}_{2} \mathrm{O}$, and intermittent doses of fen- 

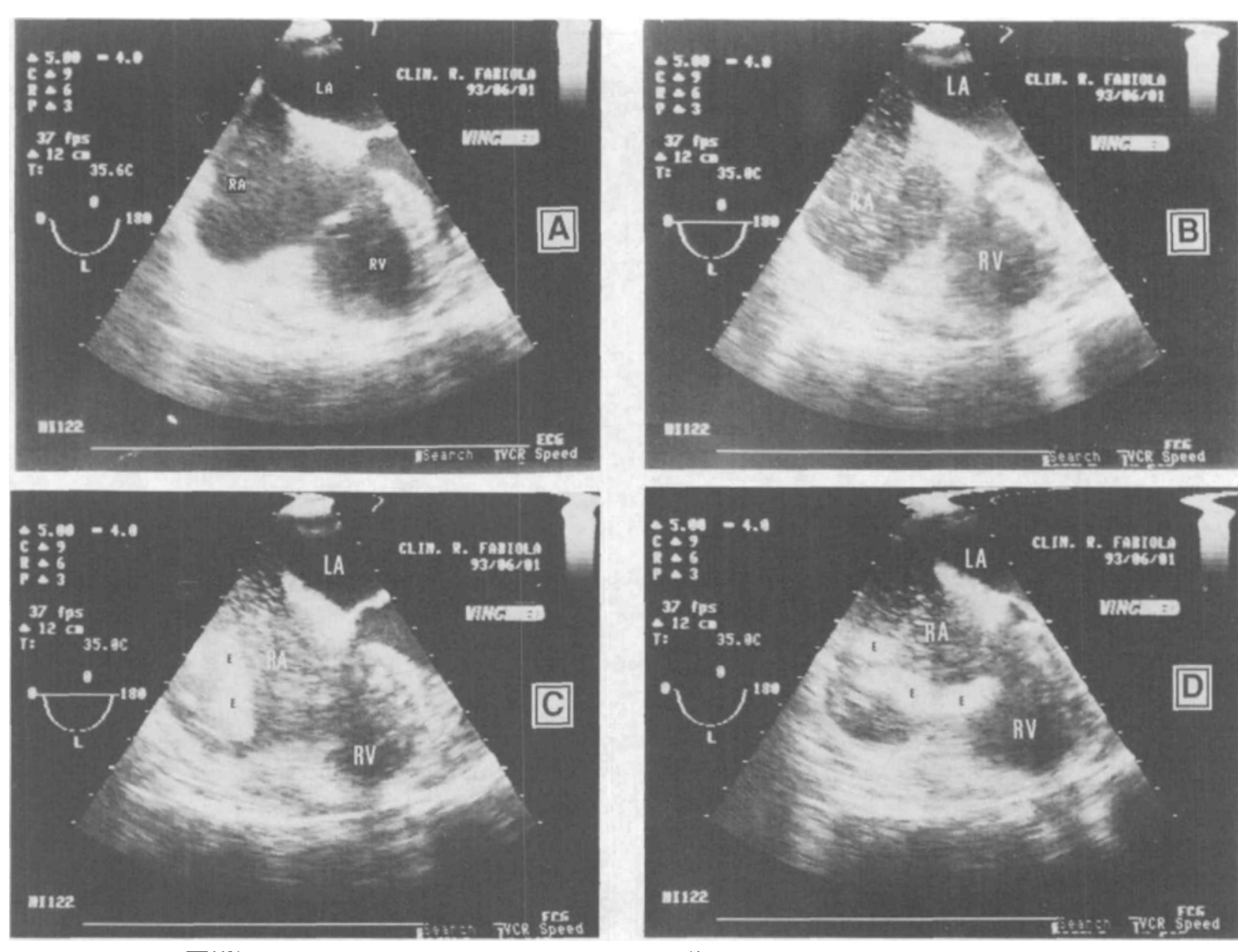

FIGURE I Four-chamber transoesophageal echocardiographic views showing embolism during total hip arthroplasty: (A) control view, (B) "snow flurry" in the right atrium, (C) small and large emboli in the right atrium, (D) large emboli in the right atrium with delayed passage at tricuspid valve. $\mathrm{RA}=$ right atrium; $\mathrm{RV}=$ right ventricle; $\mathrm{LA}=$ left atrium; $\mathrm{SF}=$ snow flurty; $\mathrm{E}=$ embolus.

tanyl (50 to $100 \mu \mathrm{g})$. Ventilation was controlled with a tidal volume of $10 \mathrm{ml} \cdot \mathrm{kg}^{-1}$ to maintain an end-tidal $\mathrm{CO}_{2}$ $\left(\mathrm{PETCO}_{2}\right)$ of $4.5-5 \mathrm{kPa}(34-38 \mathrm{mmHg})$.

A 20-gauge radial artery catheter and a central venous catheter were inserted percutaneously. The hacmodynamic variables (heart rate, blood pressure, central venous pressure) and pulse oxymetry were monitored continuously. A $5-\mathrm{MHz}$ multiplanar transoesophageal echocardiographic probe (Vingmed Sonotron 750 ${ }^{\circ}$ ) was introduced to monitor cardiac function and to obtain a four-chamber view of the heart, with special attention to the right atrium, the right ventricle and the main pulmonary artery. The gain setting was optimized to avoid any artefact. Ten milliliters of agitated saline with microbubbles were then injected through the right atrial catheter at end-expiration for detection of an eventual patent foramen ovale. This resulted in prompt opacifi- cation of the right atrium and right ventricle without paradoxical passage to the left heart.

Arterial blood gas analyses and TEE were measured repeatedly during the operative procedure: before and after the placement of the acetabular (cement 1) and femoral (cement 2) component, and during relocation of the hip joint.

A normal four-chamber TEE view of the heart was seen after incision (Figure 1A). During the placement of the acetabular component, a "snow flurry" appearing in the right atrium (Figure 1B) was followed by several highly echogenic and mobile emboli of various sizes (from 5 to $10 \mathrm{~mm}$ in diameter, some of them with a vermiform shape 1 to $5 \mathrm{~cm}$ long) easily seen on Figure 1C. A similar sequence of events was observed at the time of placing the femoral component (Figure 1D) and during relocation of the hip joint. 
TABLE Blood gas analyses at different times during the procedure

\begin{tabular}{|c|c|c|c|c|c|}
\hline Blood gases & $<$ Cement I & $>$ Cement 1 & $<$ Cement 2 & $>$ Cement 2 & Relocation \\
\hline $\mathrm{pH}$ & 7.529 & 7.55 & 7.475 & 7.535 & 7.527 \\
\hline $\mathrm{PCO}_{2} \mathrm{mmHg}$ & 35.3 & 35.9 & 36.1 & 35.8 & 35.4 \\
\hline $\mathrm{SBC}$ mmol $\cdot \mathrm{L}^{-1}$ & 26.1 & 26.9 & 23.5 & 25.8 & 25.6 \\
\hline BE mmol $\cdot \mathrm{L}^{-1}$ & 1.5 & 2.5 & -1.9 & 1 & 0.7 \\
\hline $\mathrm{PO}_{2} \mathrm{mmHg}$ & 189 & 183 & 196 & 188 & 185 \\
\hline $\mathrm{O}_{2}$ SAT $\%$ & 99.8 & 99.8 & 99.8 & 99.8 & 99.8 \\
\hline
\end{tabular}

Abbreviations: SBC = standard bicarbonate; $\mathrm{BE}=$ base excess.

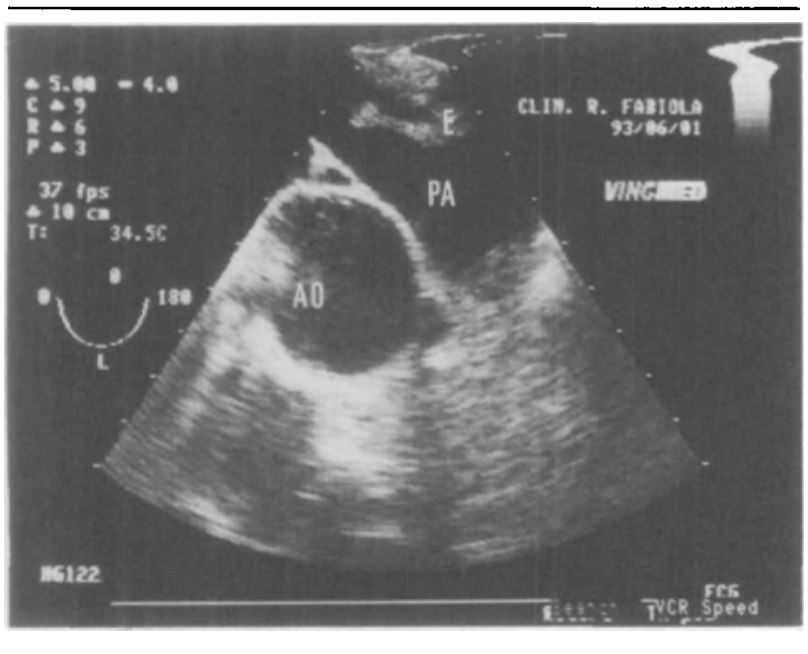

FIGURE 2 Transverse view of the pulmonary artery bifurcation. Embolus adherent to the wall of the right branch. AP = pulmonary artery; $\mathrm{AO}=$ aorta.

At skin closure, the probe was positioned to visualize the pulmonary artery bifurcation. Echogenic material was seen in the right branch of the pulmonary artery adherent to the vascular wall of the bifurcation of the main pulmonary artery (Figure 2).

No changes were observed in any haemodynamic variable. Also no desaturation was detected by pulse oxymetry or blood gases (Table) at the time of embolism and there was no decrease in $\mathrm{PETCO}_{2}$.

After completion of the operation, the patient was transferred to the surgical intensive care unit and the lungs were ventilated until complete recovery after anaesthesia. The endotracheal tube was removed when the patient was fully awake. The monitored variables were continuously recorded and there were no postoperative sequelae. A pulmonary radionuclide study performed on the first postoperative day was normal.

\section{Discussion}

This case report is in line with other studies which failed to show any haemodynamic impact of TEE detected emboli during THA. ${ }^{1,2}$ During the placement of the ace- tabular and femoral components, several emboli of various sizes were detected in the right atrium and ventricle and secondary in the pulmonary artery. The emboli were well tolerated by the patient, no haemodynamic or blood gas modifications were observed.

During insertion of the prosthesis in THA, embolization of intramedullary fat, bone marrow, methylmethacrylate, bone cement, or air can cause bone cement implantation syndrome. ${ }^{3,6}$ The syndrome is characterized by hypotension, hypoxaemia, decrease in $\mathrm{PETCO}_{2}$, cardiac arrythmias, cardiac arrest or any combination of these features. It might cause sudden death. ${ }^{7-10}$ These complications frequently occur within minutes after implantation of the methylmethacrylate bone cement and the prosthetic component.

This syndrome is due to embolism during THA, resulting from high intramedullary pressure (575 $\mathrm{mmHg}$ ). ${ }^{3,4,11}$ Ulrich et al. suggest that a venting hole in the shaft of the femur prevents the increase in pressure in the medullary space and thus also averts embolism. ${ }^{2}$ Air, fat, bone marrow, haematopoietic stem cells, endothelial cells and other intramedullary debris are embolized into the fernoral venous channels by the expanding and pressurized bone cement interface and eventually embolize to the heart and lungs or, in the case of paradoxical embolism, to the brain. ${ }^{2,13}$ Recently, Pell et al. have described a fulminating fat embolism syndrome that was associated with a paradoxical embolism through a patent foramen ovale detected by TEE during femoral fracture reduction. ${ }^{14}$ No visible intracardiac shunt was detected in our patient.

Although the nature of the embolic materials cannot be determined with certainty by ultrasounds, the vermiform shape of type A of the highly echogenic material, observed in this case, is compatible with a venous thromboembolism. . $^{15,16}$

Transoesophageal echocardiography is a new imaging technique that is gaining increasing popularity as an intraoperative monitor of cardiac function in high risk patients, for detection of ischaemia, for assessing left ventricular preload, afterload, cardiac output and ejection fraction. ${ }^{17}$ Because of its high resolution and excellent 
image quality, TEE currently represents the method of choice for patent foramen ovale detection. ${ }^{18}$ However, the equipment is expensive and requires specific technical and interpretative expertise.

This case report suggests that the presence of emboli detected by TEE in the right heart and pulmonary artery appears to have no adverse sequelae. So far, further studies are required to determine therapeutic strategies in patients with a patent foramen ovale.

\section{Acknowledgment}

The authors thank Henry C. Labasse, M.D., for his assistance in the completion of this manuscript.

\section{References}

1 Ereth $M H$, Weber JG, Abel MD, et al. Cemented versus noncemented total hip arthroplasty-embolism, hemodynamics, and intrapulmonary shunting. Mayo Clin Proc 1992; 67: 1066-74.

2 Ulrich $C$, Burri $C$, Wörsdörfer $O$, Heinrich $H$. Intra- operative transesophageal two-dimensional echocardiography in total hip replacement. Arch Orthop Trauma Surg 1986; 105: 274-8.

3 Rinecker $H$. New clinico-pathophysiological studies on the bone cement implantation syndrome. Arch Orthop Trauma Surg 1980; 97: 263-74.

4 Orsini EC, Byrick RJ, Mullen JBM, Kay JC, Waddell JP. Cardiopulmonary function and pulmonary microemboli during arthroplasty using cemented or non-cemented components. J Bone Joint Surg Am 1987; 69: 822-32.

5 Kallos T, Enis JE, Gollan F, Davis $J H$. Intramedullary pressure and pulmonary embolism of femoral medullary contents in dogs during insertion of bone cement and a prosthesis. J Bone Joint Surg Am 1974; 56: 1363-7.

6 Herndon JH, Bechtol CO, Crickenberger DP. Fat embolism during total hip replacement: a prospective study. $\mathbf{J}$ Bone Joint Surg Am 1974; 56: 1350-62.

7 Patterson BM, Healey JH, Cornell CN, Sharrock NE. Cardiac arrest during hip arthroplasty with a cemented long-stem component: a report of seven cases. J Bone Joint Surg Am 1991; 73: 271-7.

8 Duncan JA. Intra-operative collapse or death related to the use of acrylic cement in hip surgery. Anaesthesia 1989; 44: 149-53.

9 Coventry $M B$, Beckenbaugh RD, Nolan DR, Istrup DM. 2,012 Total hip arthroplasties: a study of postoperative course and early complications. J Bone Surg Am 1974; 56 : 273-84.

10 Byrick RJ, Mullen JBM, Wigglesworth DF. Pulmonary and systemic fat embolism after cemented arthroplasty. Can J Anaesth 1993; 40: A18.

11 Tronzo $R G$, Kallos $T$, Wyche $M Q$. Elevation of intramedullary pressure when methylmethacrylate is inserted in total hip arthroplasty. J Bone Joint Surg Am 1974; 56 : 714-8.

12 Modig J, Busch C, Olerud S, Saldeen T, Waernbaum G. Arterial hypotension and hypoxaemia during total hip replacement: the importance of thromboplastic products, fat embolism and acrylic monomers. Acta Anaesthesiol Scand 1975; 19: 28-43.

13 Pell ACH, Christie J, Keating JF, Sutherland GR. The detection of fat embolism by transoesphageal echocardiography during reamed intramedullary nailing. A study of 24 patients with femoral and tibial fractures. J Bone Joint Surg Br 1993; 75: 921-5.

14 Pell AC, Hughes D, Keating J, Christie J, Busuttil A, Sutherland $G R$. Brief report: fulminating fat embolism syndrome caused by paradoxical embolism through a patent foramen ovale. N Engl J Med 1993; 329: 926-9.

15 The European Working Group on Echocardiography. The European Cooperative Study on the clinical significance of right heart thrombi. Eur Heart J 1989; 10: 1046-59.

16 Parmet JL, Berman AT, Horrow JC, Harding S, Rosenberg $H$. Thromboembolism coincident with tourniquet deflation during total knee arthroplasty. Lancet 1993; 341: 1057-8.

17 Clements FM, de Bruijn NP. Perioperative evaluation of regional wall motion by transesophageal two-dimensional echocardiography. Anesth Analg 1987; 66: 249-61.

18 Chenzbraun A, Pinto FJ, Schnittger I. Biplane transesophageal echocardiography in the diagnosis of patent foramen ovale. J Am Soc Echocardiogr 1993; 6: 417-21. 